\title{
Development, Characterization, and Pharmacological Investigation of Sesamol and Thymol Conjugates of Mefenamic Acid
}

\author{
Nija B. ${ }^{1}$, Arun Rasheed ${ }^{2}$, Kottaimuthu A. ${ }^{3}$ \\ 1, 2 Department of Pharmaceutical Chemistry, Al Shifa College of Pharmacy, Perinthalmanna, Malappuram \\ District, Kerala, India. ${ }^{3}$ Department of Pharmacy, Annamalai University, Annamalai Nagar, Tamilnadu, India.
}

\section{ABSTRACT}

\section{BACKGROUND}

Prodrug technology was extensively employed in the drug discovery processes and many approved drugs in the pharmaceutical industry were developed by the prodrug based synthetic approach. The current research work investigates the effect of the prodrug approach on the mefenamic acid by synthesizing the ester conjugates with natural antioxidants such as sesamol and thymol.

\section{METHODS}

Synthesis of two ester prod rugs, mefenamic acid-sesamol conjugate and mefenamic acid-thymol conjugate by coupling method using DCC / DMAP, subjected to physicalchemical characterization, spectral characterization (IR, ${ }^{1} \mathrm{H}$ NMR, ${ }^{13} \mathrm{C}$ NMR and Mass spectra), in-silico studies, in-vivo biodistribution studies and pharmacological evaluation such as anti-inflammatory, ulcerogenecity, activity in the brain as well as histopathological evaluation.

\section{RESULTS}

The ester prodrugs of mefenamic acid which upon administration would release the parent drug as a result of enzymatic or non-enzymatic hydrolysis in the desired areas with enhanced anti-inflammatory activity and reduction in the gastro intestinal toxicity. In-silico studies showed the docking score of mefenamic acid on the betasecretase enzyme is -7.834 and the bio-distribution study showed the enhanced distribution of the mefenamic acid in the brain. Pharmacological study and histopathology studies using the brain tissues showed the protective effect of mefenamic acid in the brain.

\section{CONCLUSIONS}

Antioxidant conjugates of mefenamic acid showed sustained release of the mefenamic acid and enhanced anti-inflammatory activity with reduction in the gastric toxicity. The present investigation also revealed that the enhanced transport profile across blood brain barrier and considerable protective effect in the brain against neurodegenerative conditions.

\section{KEY WORDS}

Pro Drug, Anti Inflammatory, Ulcerogenecity, Antioxidants, Neurodegeneration
Corresponding Author: Dr. Kottaimuthu A, Associate Professor, Department of Pharmacy, Annamalai University, Annamalainagar - 608 002, Tamilnadu, India, E-mail: akottaimuthu@gmail.com

DOI: $10.14260 / \mathrm{jemds} / 2020 / 857$

How to Cite This Article:

Nija B, Rasheed A, Kottaimuthu A. Development, characterization and pharmacological investigation of sesamol and thymol conjugates of mefenamic acid. $J$ Evolution Med Dent Sci 2020;9(52):39093916, DOI: 10.14260/jemds/2020/857

Submission 02-09-2020,

Peer Review 05-11-2020,

Acceptance 11-11-2020,

Published 28-12-2020.

Copyright (C) 2020 NIja B. et al. This is an open access article distributed under Creative Commons Attribution License [Attribution 4.0 International (CC BY 4.0)] 


\section{BACKGROUND}

Mefenamic Acid, (MA) [2- (2, 3-dimethylphenyl)] amino benzoic acid) is a Non-Steroidal Anti-Inflammatory Drug (NSAIDs) having pharmacological activities like analgesic activity, anti-inflammatory activity, anti-pyretic activity and used for treating the muscular aches, menstrual cramps, head ache and dental pain. ${ }^{1}$ The structure activity relationship of the mefenamic acid proved the null effect of free carboxylic acid functional group in the anti-inflammatory activity but several side effect is there for producing the gastric toxicity such as ulceration. ${ }^{2}$ So the prodrug based synthetic approach masked the free carboxyl functional group by producing the ester conjugates of MA, MF-S and MF-T. The literature survey also showed the significant role of NSAIDs in the brain against neurodegenerative conditions but that is limited due to the hydrophilic nature. So, the prodrug based synthetic approach converted them into lipophilic and that is having the ability to cross BBB (Blood Brain Barrier). ${ }^{3}$

The conjugates used for synthesizing the ester prodrugs of MA were the natural antioxidants sesamol and thymol. The use of natural antioxidants in the diet can reduce the risk of various serious diseases conditions by scavenging the free radicals from the tissues and prevent oxidation. Most of the natural antioxidants are polyphenols, carotenoids and vitamins and in prod rug synthetic scheme, the use of this has conjugates can diminish the risk factor after hydrolysis of the prod rug at the site of action. Sesamol and thymol are phenolic natural antioxidants having wide variety of pharmacological activities. Literature survey showed that sesamol is having wide range of pharmacological activities such as anti-oxidant, anti-cancer, neuro-protective activity, cardio-protective, antiinflammatory, anti-depressant, anti-amnesia, anti-ulcer, antianxiolytic etc. ${ }^{4}$ Thymol also having several therapeutic activities such as anti-inflammatory, anti-oxidant, antihyperlipidaemic etc. ${ }^{5}$ So the utilization of natural antioxidants as conjugates may produce synergistic pharmacological activity and the improved transport properties with the reduction of side effects.

Prodrug technology was extensively used in the drug discovery processes and many approved drugs in the pharmaceutical industry were developed by the prodrugbased concept. The usefulness and importance of this prod rug technology can be understood from the medicines used in the market such as angiotensin converting enzyme inhibitors, sulphasalazine for the management of ulcerative colitis, estradiol, dopamine etc. But the survey also indicated that limited clinical trials were conducted during past some years from the drugs developed from prodrug-based technology. But the prodrugs can be successfully overcoming the barriers of drug targeting and drug delivery to elicit the desired pharmacological activity. Prodrug are the inactive form of the active ingredient and that release the active drug by enzymatic or chemical conversion. ${ }^{6}$ Prodrug technology is effectively utilized for synthesizing the antioxidant conjugates of MA that can overcome the side effects of NSAIDs and produced the enhanced therapeutic profile. The use of NSAIDs showed many side effects such as gastro-intestinal bleeding, cardio-vascular side effects, and drug induced nephro-toxicity etc. ${ }^{7}$ among that, many side effects can be reduced by the prodrug technology through the synthesis of ester and amide prodrug.
Ester prodrug having many advantages over other linkages such as susceptible to hydrolysis and yield good drug concentration after absorption and showed resistance to hydrolysis at absorption phase. This research work subjected to the modification of the mefenamic acid with the natural antioxidants, sesamol and thymol, synthesized two ester prodrug that is having enhanced therapeutic profile, transport profile and reduction in the toxicity profile.

\section{METHODS}

\section{Chemicals and Instruments}

The drug MA was obtained from TCI (Tokyo Chemical Industry) Chemicals (India) Pvt. Ltd., Chennai, Tamilnadu. The antioxidant 4-methyl umbelliferone was obtained from Sigma Aldrich Chemicals Pvt. Ltd. Mumbai. The FTIR spectra of the compounds were recorded on IR spectrometer (Bruker, software: Opus), at Al Shifa College of Pharmacy, Kerala. The elemental analysis by using elemental analyser (Thermo Finnigan, Italy, FLASH EA 1112 series) was done in Sophisticated Analytical Instrumentation Facility (SAIF), Lucknow. ${ }^{1}$ H NMR (cryo-magnet spectrometer, Bruker), CNMR spectra (cryo-magnet spectrometer, Bruker) and MASS spectra (Micromass Q-Tof Micro) were performed in SAIF Panjab University, Chandigarh. The melting points of the prodrug was recorded using melting point apparatus (Sigma scientific products, Tamilnadu), Al Shifa College of pharmacy, Kerala. The absorbance was measured in the UV spectrophotometer (Shimadzu, Japan). Determination of physicochemical properties and the pharmacological evaluations were carried out in Department of Pharmaceutical Chemistry and Department of Pharmacology, Al Shifa College of Pharmacy. The histo-pathological studies were carried out in department of Pathology, KIMS and Al Shifa hospital, Kerala.

\section{Synthesis of MA-Antioxidant Prodrug}

This research work developed three ester prodrugs of NSAID, mefenamic acid by conjugating with two antioxidants sesamol and thymol thus mefenamic acid-sesamol prodrug [MF-S], and mefenamic acid-thymol prodrug [MF-T]. The method used for the synthesis of ester prodrugs was DCC / DMAP coupling method. To a stirred solution of $10 \mathrm{mmol}$ of carboxylic acid in $15 \mathrm{ml}$ of anhydrous dichloromethane (DCM) $110 \mathrm{mg}$ DMAP and $10 \mathrm{mmol}$ of sesamol was added. Then $10 \mathrm{mmol}$ of DCC was added to the reaction mixture at $0-8^{0} \mathrm{C}$, which is then stirred for 5 minutes at $0-8^{0} \mathrm{C}$ and for $3 \mathrm{hr}$. at $20-25^{0} \mathrm{C}$. After completing the reaction, the precipitated urea was filtered off and the filtrate was evaporated. The residue was taken in 10 ml DCM and washed with saturated sodium bicarbonate solution and then dried over magnesium sulphate. The solvent is removed by evaporation and the ester isolated by recrystallization. Before the recrystallization the product was washed with alcohol to remove excess of sesamol. If the product after synthesis was sticky, it was washed with petroleum ether two or three times. The same procedure was used for the synthesis of MF-T and that is shown in the scheme of the synthesis.8,9 


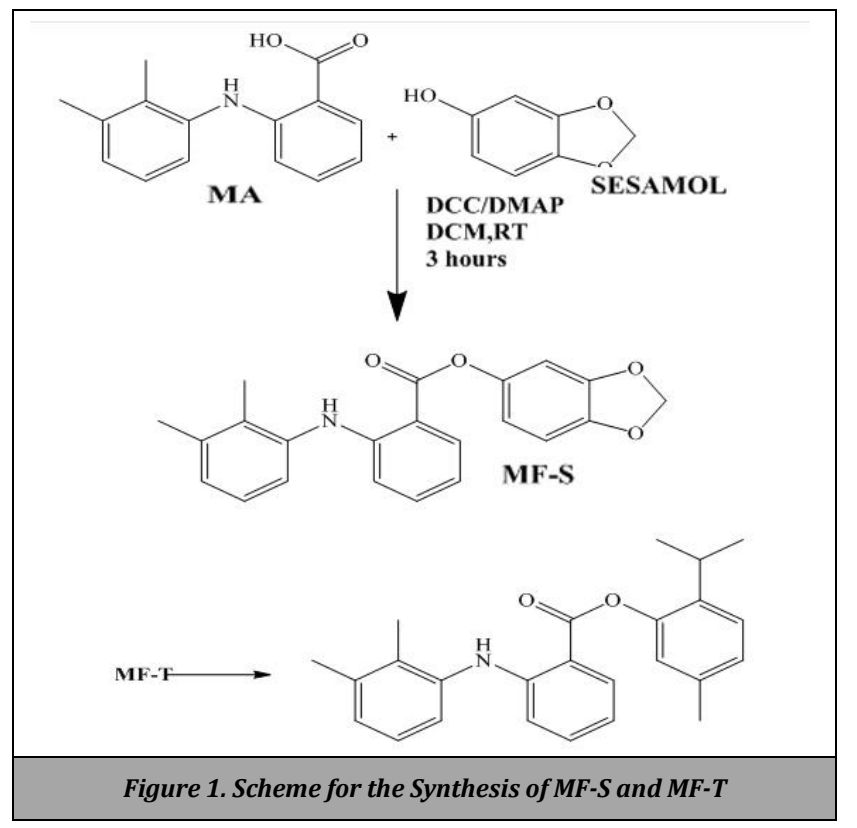

Physical-Chemical Characterization of MA, MF$S$ and MF - T

The physical as well as chemical properties of the synthesized prodrugs was done by different methods such as solubility, thin layer chromatography, partition coefficient determination, melting point determination, elemental analysis and spectral characterization and the produced data was compared with that of the parent drug, mefenamic acid. Solubility is an important parameter in the case of drugs that can be used for the formulation. In this study the drug and synthesized compounds were subjected to solubility analysis in different solvents such as $0.1 \mathrm{~N} \mathrm{NaOH}, 0.1 \mathrm{~N} \mathrm{HCl}$, ethanol, methanol, ether, ethyl acetate, chloroform, acetone, DMF and water. ${ }^{10}$ Thin layer chromatography was done to check the progression of the reaction and also confirm the purity of the synthesized compounds that was done on the pre coated silica G plates. The visualization was done by UV chamber. The solvent system used here was ethyl acetate: hexane 1:2.11 The determination of melting point of the synthesized compounds was compared with that of the reactants to confirm the formation of the product and also assure the purity of the synthesized compounds. ${ }^{12}$ The determination of partition coefficient aim is to attain the knowledge of the lipophilic profile of the synthesized compounds and that was done by shake flask method in which n-octanol saturated with phosphate buffer ( $\mathrm{pH}$ 7.4). The concentration of the drug and each prodrug was monitored by measuring the absence using a UV-VISIBLE spectrometer. ${ }^{13}$ The elemental data analysis was done to find the percentage of $\mathrm{C}, \mathrm{H}, \mathrm{O}$ and $\mathrm{N}$ in the prodrugs. The structure of the synthesized compounds was confirmed by different spectral analysis such as IR, ${ }^{1} \mathrm{H}$ NMR, ${ }^{13} \mathrm{C}$ NMR spectra and Mass spectra. The spectral data of the prodrugs were compared with that of the standard MA affirming the formation of the compounds by the scheme 1 .

\section{Molecular Modelling and ADME Studies}

The docking studies were conducted to know about the interaction of the NSAID, MA in beta-secretase enzyme which is a cleavage enzyme of amyloid precursor protein. The docking score of the drug in the beta-secretase enzyme was found out by Ligprep, Glide, Prime, and Virtual Screening Workflow. Optimization of ADME is very much significant in the drug development process. QikProp is an in-silico method used for ADME optimization analysis of active lead molecules. All the synthesized molecules were subjected to pharmacokinetic parameters such as absorption, distribution, metabolism and excretion by use of Qikprop (Schrodinger, USA, 2015).14

\section{Bio-Distribution}

The bio-distribution of the synthesized prodrugs in the brain was done by in-vivo method and the parameter used to assess the brain distribution of the conjugates by Brain Targeting Efficiency (BTE = concentration of drug in the brain / concentration of the drug in the plasma) and that was done as per the procedure explained in Xuan Zhang et al., 2012.15

\section{Pharmacological Evaluation}

The ester prodrugs of MA were subjected to anti-inflammatory activity, anti-ulcerogenecity and analysis of biochemical parameters. The Wistar albino rat was used for the study and all the animal experiments were conducted after obtaining the institutional ethical committee approval (Reg.No. 1195/PO/Re/S/08/CPCEA), Al Shifa College of pharmacy, Kerala.

\section{Anti-Inflammatory Activity}

The screening of anti-inflammatory activity was done by using carrageenan induced paw oedema method. In this screening method, inflammation was induced by $0.1 \mathrm{ml}, 1 \% \mathrm{w} / \mathrm{v}$ of carrageenan was used as inducing agent. Normal saline treated group act as control group and initially the volume of paw was measured using Vernier calliper. MA (50 mg / Kg) was administered for the standard group and corresponding doses of prodrugs were administered to the respective groups. After 30 minutes of administration, the carrageenan solution in normal saline was administered to each group. The volume of swelling was measured at 0,1,2, 4 and 6 hours and the mean increase in the volume of test compared with that of the standard. ${ }^{15}$ Percentage inhibition was calculated by $(1-\mathrm{a} / \mathrm{b})$ 100 where ' $a$ ' is mean increase in the paw thickness of treated groups and ' $b$ ' is the mean increase in the paw thickness of the control group. ${ }^{16}$

\section{Anti-Ulcerogenic Study}

Gastrointestinal toxicity expressed as lesions produced by the drugs and prodrugs and the mucosal damage was examined by using of an electron microscope. The severity of the gastric toxicity was measured by the parameter mean ulcer index and that was calculated by the following way. Grade 1: $1 \mathrm{~mm}$ erosions, grade 2: $1-2 \mathrm{~mm}$ erosions and grade 3 : more than 2 $\mathrm{mm}$ erosions. The UI was calculated as UI $=[1 \times($ number of lesions of grade 1$)+2 \times($ number of lesions of grade 2$)+3 \times$ (number of lesions of grade 3) / 10].17
} 


\section{Activity in Brain}

The distributed NSAIDs showed the activity in the brain can be evaluated by using behavioural test, antioxidant test and histopathology of the brain cortex valuation. The model used for pharmacological screening was aluminium chloride induced neurotoxicity model. ${ }^{18}$ The animals were divided into five groups and each contain six animals. The Group I received normal saline which acts as control, Group II received aluminium chloride $(50 \mathrm{mg} / \mathrm{Kg}$ ) that acts as a negative control, Group III, IV and V received MA, MF-S and MF-T respectively. This chronic neurotoxicity model was conducted and evaluated for 90 days.

\section{Behavioural Tests \\ Open Field Tests}

Rats were placed in the open field apparatus and after placing the animals, they were allowed to move without any disturbance for 5 minutes and number of head dips, line crossing and rearing were counted. ${ }^{19}$

\section{Marble Burying Assay}

The marble burying test is a simple behavioural test conducted in rodents, especially rats and mice are exposed to glass marbles placed on thick bedding materials. Thirty clean glass marbles were arranged evenly on the bedding. After 30 minutes exposure to the marbles, mice were removed, and unburied marbles were counted. A marble was considered buried if its two-third size was covered with saw dust and the total number of marbles buried was considered as an index of locomotion. ${ }^{20}$

\section{Water Maze Test}

The rats were placed in the apparatus and escape latency was monitored. The apparatus consists of a large circular pool including a wooden material below. The experiment was conducted by the procedure explained by Nunez J et al. ${ }^{21}$

\section{Antioxidant Parameters}

For the in vivo test of antioxidant parameters, after behavioural study the mice were sacrificed, and brain tissue homogenate was prepared with normal saline and centrifuged. The supernatant was used for the tests. The superoxide dismutase and catalase were tested as per the procedure explained in the Khan R A et al., 2012 and Portia et al., 2018 respectively. Statistical significance of all studies was done by ANOVA and the values were expressed as mean $\pm \mathrm{SD}^{22,23,24}$

\section{Histopathology of Brain Cortex}

Histopathology of the brain cortex of the different treated groups were examined by haematoxylin-eosin stain and monitored under electron microscope. ${ }^{25}$

\section{Statistical Analysis}

Results were communicated as mean \pm SD of 6 rats in every group. The statistical significance between the groups was analyzed by utilizing One Way Analysis of Variance (ANOVA), followed by Dunnett's multiple correlation test. Significance level was fixed at 0.05 .

\section{RESULTS}

\section{Physical and Chemical Characterization}

The two ester prodrugs MF-S and MF-T were successfully synthesized, and characterization was done, and the results were given in table 1 . The two ester prodrugs, MF-S and MF-T were pale yellowish in colour and showed remarkable solubility in organic solvents than aqueous solvents. The significant difference in the melting point of the products from the reactants and single spot obtained in the thin layer chromatographic studies revealed the preliminary knowledge about the synthesis and purity of the MF-S and MF-T. The log $P$ value of the synthesized compounds and the MA was done by partition coefficient study and indicated the enhanced lipophilicity of the synthesized ester prodrugs. The spectral studies confirmed the structure of the synthesized MF-S and MF-T.

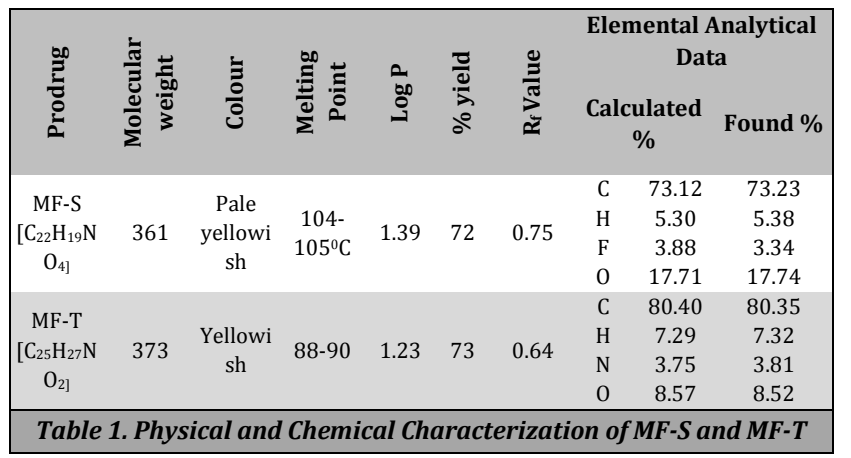

MF-S (benzo [d] [1,3] - dioxol -5-yl-2- ( (2,3-dimethyl phenyl) amino) benzoate): FTIR ( $\left.\mathrm{cm}^{-1}, \mathrm{KBr}\right): 3317$ (-NH), 2924 (aromatic C-H), 2853 (Aliphatic C-H) and 1684 (C O ester); ${ }^{1} \mathrm{HNMR}\left(\mathrm{CDCl}_{3,}\right): 2.31(\mathrm{~S}, 3 \mathrm{H}), 2.15(\mathrm{~S}, 3 \mathrm{H}), 5.99(\mathrm{~S}, 2 \mathrm{H}$ in the dioxole ring), $6.80(\mathrm{~d}, \mathrm{~J}=8.5$, benzene ring $1 \mathrm{H}), 6.73(\mathrm{t}, \mathrm{J}=6.8$, $1 \mathrm{H}), 6.82(\mathrm{~d}, \mathrm{~J}=8.35,1 \mathrm{H}), 8.15(\mathrm{~d}, \mathrm{~J}=6.7,1 \mathrm{H}), 7.30(\mathrm{t}, \mathrm{J}=7.1$, $1 \mathrm{H}), 7.10(\mathrm{t}, \mathrm{J}=7.1,1 \mathrm{H}), 7.15(\mathrm{~d}, \mathrm{~J}=7.75,1 \mathrm{H}), 9.16(\mathrm{~s}, 1 \mathrm{H}), 6.65$ $(\mathrm{d}, \mathrm{J}=8.35,1 \mathrm{H}), 7.01(\mathrm{~d}, \mathrm{~J}=7.35,1 \mathrm{H}), 6.70(\mathrm{~s}, 1 \mathrm{H})$; Mass $(\mathrm{m} /$ z) :362; ${ }^{13}$ CNMR:14.03, 20.64, 101.77, 104.19, 108.02, 109.58, $113.82,114.39,116.21,123.22,125.99,127.05,131.89$, 132.57, 135, 138.31, 138.39, 145.07, 145.48, 148.19150.26, 167.72 .

MF-T (2-isopropyl-5-methyl phenyl2- ( (2,3-dimethyl phenyl) amino) benzoate): FTIR $\left(\mathrm{cm}^{-1}, \mathrm{KBr}\right): 3324(-\mathrm{NH}) 3070$ (aromatic C-H), 2921(Aliphatic C-H) and 1671 (C O ester); ${ }^{1} \mathrm{HNMR}\left(\mathrm{CDCl}_{3}\right.$ ) $): 9.23(\mathrm{~S}, 1 \mathrm{H}), 8.22(\mathrm{~d}, \mathrm{~J}=6.55,1 \mathrm{H}), 7.32(\mathrm{t}, \mathrm{J}=$ $7.2,1 \mathrm{H}), 7.25(\mathrm{t}, \mathrm{J}=6.8,1 \mathrm{H}), 7.19(\mathrm{~d}, \mathrm{~J}=7.8,1 \mathrm{H}), 7.10(\mathrm{~d}, \mathrm{~J}=7.6$, 1H), $7.08(\mathrm{~d}, \mathrm{~J}=8,1 \mathrm{H}), 7.02(\mathrm{~d}, \mathrm{~J}=7.45,1 \mathrm{H}), 6.95(\mathrm{~s}, 1 \mathrm{H}), 6.83$ $(\mathrm{d}, \mathrm{J}=8.55,1 \mathrm{H}), 6.74(\mathrm{t}, \mathrm{J}=7.15,1 \mathrm{H}), 3.10(\mathrm{~m}, \mathrm{~J}=6.9,1 \mathrm{H}), 2.35$ $(\mathrm{s}, 3 \mathrm{H}), 2.31(\mathrm{~s}, 3 \mathrm{H}), 2.17(\mathrm{~s}, 3 \mathrm{H}), 1.24(\mathrm{dd}, \mathrm{J}=6.9,6 \mathrm{H})$; ${ }^{13}$ CNMR:167.60, 150.21, 147.98, 138.48, 138.29, 137.53, 136.68, 134.87, 132.44, 131.86,127, 126.92, 126.55, 125.93, 123.08, 123.07, 116.26, 113.84, 10.9.88, 27.26, 23.16, 23.16, 20.92, 20.64, 14.01; Mass (m / z):374

\section{Molecular Modelling and ADME Studies}

The molecular modelling study revealed that the NSAID, MA is able to bind to the active site of the Beta-Secretase enzyme, with a docking score of -10.349 and - 7.834 respectively. Insilico and molecular modelling studies showed that in addition to its anti-inflammatory activity it also inhibits the beta 
secretase enzyme which produces the beta amyloid protein in the neuronal cells. So based on the results, if these molecules can directly target in to the brain may give potential therapeutic activity in the degenerated conditions.

Also the pharmacokinetic parameters were found out by Qikprop and the predicted MDCK permeability of blood brain barrier was find out and the range accepted was below 25 is poor, above 500 is great that also indicated the enhanced permeability of the prodrugs ie MA-193.17, MF-S-3138.16 and MF-T-4189.51. The pharmacokinetic parameters showed significant variation of the values between the drugs and the synthesized ester compounds, MF-S and MF-T.

\section{Bio-Distribution and Brain Targeting Efficiency}

The distribution of the drug and prodrugs can be evaluated by bio-distribution conducted in vivo method. The parameter used for evaluating the brain distribution of the drug and pro drugs is brain targeting efficiency. The $\left(\mathrm{C}_{\text {brain }} / \mathrm{C}_{\text {plasma }}\right)_{\mathrm{MA}}$ ratios of the $10 \mathrm{~min}$ after administration MA, MF-S and MF-T pro drugs were $0.046 \pm 0.014,0.491 \pm 0.013$ and $0.1366 \pm 0.015$ respectively.

\section{Pharmacological Evaluation}

Anti-Inflammatory Activity

MA and the two natural antioxidants are having antiinflammatory activity and the prodrug technology revealed the enhanced anti-inflammatory activity provided by the two ester prodrugs MF-S and MF-T. The results of the comparative approach were shown in the table 2. From the six hours of observations, it was concluded that the two ester prodrugs showed about 70 percentage of activity compared with that of the parent drug thus provide synergistic activity and also the study proved the sustained release of the drug and conjugate.

\begin{tabular}{|c|c|c|c|c|c|c|c|c|}
\hline \multirow[b]{2}{*}{ Group } & \multirow{2}{*}{ Prodrug } & \multirow{2}{*}{$\begin{array}{c}\text { Dose } \\
\text { (mg p.o.) }\end{array}$} & \multicolumn{5}{|c|}{ Anti-Inflammatory Activity (\%) ${ }^{b}$} & \multirow{2}{*}{$\begin{array}{l}\text { Mean } \\
\text { Ulcer } \\
\text { Index }\end{array}$} \\
\hline & & & $1 \mathrm{~h}$ & $2 \mathrm{~h}$ & $3 \mathbf{h}$ & $4 \mathrm{~h}$ & $6 \mathrm{~h}$ & \\
\hline I & $\begin{array}{l}\text { Normal } \\
\text { Control }^{\mathrm{a}}\end{array}$ & $\begin{array}{l}\text { Normal } \\
\text { saline }\end{array}$ & - & - & - & - & - & 0 \\
\hline II & MA & 8.0 & $\begin{array}{c}49.0 \pm \\
1.2\end{array}$ & $\begin{array}{c}48.0 \pm \\
1.1\end{array}$ & $\begin{array}{c}45.8 \pm \\
1.9\end{array}$ & $\begin{array}{c}43.3 \pm \\
1.2\end{array}$ & $\begin{array}{c}42.5 \pm \\
1.4\end{array}$ & $\begin{array}{c}23.9 \pm \\
1.2\end{array}$ \\
\hline III & MF-S & 10.5 & $\begin{array}{c}44.1 \pm \\
1.3^{\mathrm{c}}\end{array}$ & $\begin{array}{c}51.2^{ \pm} \\
1.1^{\mathrm{c}}\end{array}$ & $\begin{array}{c}60.0 \pm \\
1.2^{\mathrm{c}}\end{array}$ & $\begin{array}{c}69.3 \pm \\
1.3^{\mathrm{c}}\end{array}$ & $\begin{array}{c}75.5^{\mathrm{t}} \\
1.4^{\mathrm{c}}\end{array}$ & $\begin{array}{l}4.5^{\mathrm{t}} \\
1.5^{\mathrm{b}}\end{array}$ \\
\hline IV & MF-T & 13.0 & $\begin{array}{c}42.0 \pm \\
1.5^{c} \\
\end{array}$ & $\begin{array}{c}51.0 \pm \\
1.7^{c} \\
\end{array}$ & $\begin{array}{c}56.8 \pm \\
1.8^{c} \\
\end{array}$ & $\begin{array}{c}59.4 \pm \\
1.1^{\mathrm{c}} \\
\end{array}$ & $\begin{array}{c}68.7 \pm \\
1.4^{c} \\
\end{array}$ & $\begin{array}{c}5.1 \pm \\
1.41 .1^{\mathrm{b}} \\
\end{array}$ \\
\hline & & $D a$ & Anti-I & flamm & atory & ctivity & & \\
\hline
\end{tabular}

bEach value represented as mean \pm SD of six observed data. crepresents the comparison between the groups III, IV vs. group II. Also, brepresents the comparison between the groups III, IV vs group II. ${ }^{c} \mathrm{p},{ }^{\mathrm{b}} \mathrm{p}<0.05$ and significance found out by ANOVA followed by Dunnett's test.

\section{Ulcerogenic Activity}

The main risk factor of NSAIDs is the production of gastric ulcers and this study made comparison between the production of ulcers by the parent drug, MA and the antioxidant conjugated MA derivatives through the parameter mean ulcer index. The ulcer production was visually monitored. The MA has the mean ulcer index 23.9 and MF-S and MF-T have 4.5, 5.1 respectively. The comparative study revealed the prodrug-based approach successfully reduces the side effect, gastric ulceration, produced by the MA.

\section{Activity in Brain}

Pharmacological investigation was done for monitoring the behavioural parameters, biochemical evaluation i.e. antioxidant parameters and histopathology of brain to confirm the activities of the synthesized pro drugs. The results were in the Table 3.

\begin{tabular}{|c|c|c|c|c|c|c|c|}
\hline \multirow[t]{2}{*}{ Group } & \multicolumn{3}{|c|}{ Open Field Test } & \multirow{2}{*}{$\begin{array}{c}\text { Marble } \\
\text { Burying } \\
\text { Test }\end{array}$} & \multirow{2}{*}{$\begin{array}{l}\text { Water } \\
\text { Maze Test } \\
\text { (Time in } \\
\text { Seconds) }\end{array}$} & \multicolumn{2}{|c|}{$\begin{array}{c}\text { Antioxidant } \\
\text { Activity } \\
\text { [U / mg Protein] }\end{array}$} \\
\hline & $\begin{array}{c}\text { Head- } \\
\text { Dips }\end{array}$ & $\begin{array}{l}\text { Rear- } \\
\text { ing }\end{array}$ & $\begin{array}{c}\text { Line } \\
\text { Crossing }\end{array}$ & & & SOD & Catalase \\
\hline & $9.0 \pm$ & $22.0 \pm$ & $36.0 \pm$ & $28.0 \pm$ & 55.18 & $7.66 \pm$ & $2.31 \pm$ \\
\hline & 0.058 & 0.068 & 0.039 & 0.043 & 0.08 & 0.042 & 0.089 \\
\hline \multirow{2}{*}{ II } & $2.0 \pm$ & $8.0 \pm$ & $10.0 \pm$ & $7.0 \pm$ & $120.76 \pm$ & $1.54 \pm$ & $0.43 \pm$ \\
\hline & $0.046^{\mathrm{a}}$ & $0.063^{\mathrm{a}}$ & $0.041^{\mathrm{a}}$ & $0.078^{f}$ & $0.076^{\mathrm{m}}$ & $0.046^{\mathrm{a}}$ & $0.059^{\mathrm{a}}$ \\
\hline \multirow{2}{*}{ III } & $3.0 \pm$ & $9.0 \pm$ & $13.0 \pm$ & $10.0 \pm$ & $111.93 \pm$ & $1.99 \pm$ & $0.49 \pm$ \\
\hline & $0.047 \mathrm{~b}$ & $0.068^{\mathrm{b}}$ & $0.044^{\mathrm{b}}$ & $0.087 \mathrm{k}$ & $0.072^{\mathrm{n}}$ & $0.037^{b}$ & $0.061^{\mathrm{b}}$ \\
\hline \multirow{2}{*}{ IV } & $7.0 \pm$ & $17.0 \pm$ & $31.0 \pm$ & $22.0 \pm$ & $64.58 \pm$ & $5.69 \pm$ & $1.38 \pm$ \\
\hline & $0.044^{\mathrm{c}}$ & $0.050^{c}$ & $0.057^{c}$ & $.069 \mathrm{~g}$ & $0.064^{p}$ & $0.053^{c}$ & $0.077 \mathrm{c}$ \\
\hline & $4.0 \pm$ & $10.0 \pm$ & $19.0 \pm$ & $14.0 \pm$ & $88.68 \pm$ & $2.93 \pm$ & $0.98 \pm$ \\
\hline & $0.057^{\mathrm{c}}$ & $0.065^{c}$ & $0.063^{c}$ & $0.088 \mathrm{~g}$ & $0.049^{\mathrm{s}}$ & $0.022^{\mathrm{d}}$ & $0.065^{\mathrm{d}}$ \\
\hline
\end{tabular}

\section{Marble Burying Test}

The values were expressed as the mean \pm SEM of six animals. fP $<0.001$ represents the significance of group II with Group I. $\mathrm{gP}<0.05$ represents the significance on Group V with IV. $\mathrm{kP}<$ 0.01 represents statistical significance of group III vs II.

\section{Water Maze Test}

Each value was expressed as mean \pm SEM of six animals. ${ }^{m p}<$ 0.01 for comparison of group I with the Group II. ${ }^{\mathrm{n}} \mathrm{p}<0.001$ for Group III with Group II. pP $<0.05$ represents the significance on Group IV with III. sP $<0.01$ represents statistical significance of group V vs. III.

\section{Antioxidant Activity}

Each value is expressed as the mean \pm SEM of six animals. ap $<$ 0.01 for comparison of group I with the Group II. ${ }^{b} p<0.001$ for Group III with Group II. $c$ P $<0.05$ represents the significance on Group IV with III. dP $<0.01$ represents statistical significance of group V vs. III.

Behavioural parameters were monitored by using Open field test, Marble burying test and water maze test. In open field studies, the number of head dipping, rearing and line crossing were considered for the assessment of locomotor and cognitive function. The oral administration of aluminium chloride significantly $(\mathrm{P}<0.001)$ induced the neurotoxicity when compared to the normal saline treated animals (control group). The MA treated animals showed no significant improvement in the activity profile that indicated the very limited distribution of the drug in the brain. But MF-S and MF$\mathrm{T}$ prodrugs showed improvement in habituation memory compared with the parent drug that was shown in the table 3.

Behavioural data obtained from the marble burying test is a parameter to test the locomotion. The result showed that aluminium chloride induced group had less locomotion 
compared with the control. But the synthesized ester pro drugs treated groups showed better activity than the parent drug treated group and that was shown in the table 3.

The water maze test evaluated the spatial learning and memory and the results were tabulated in table 3 and graphically represented in table 3 . The results showed that the negative control group has increased escape latency compared to the control group $(\mathrm{p}<0.01)$. The time taken to escape is decreased in the case of prodrug treated groups compared with that of MA treated groups. The synthesized ester pro drugs significant decrease in the escape latency indicated the protective effect of prodrugs in brain.

The evaluation of the antioxidant parameters showed that the enhanced activity of the natural antioxidant conjugated ester prodrugs and that provided the protective effect against the degeneration in the nerve cells. The data was given in table 3. Histopathology of brain cortex also revealed the protective nature of MA against the aluminium chloride neurode generation by conjugating with phenolic antioxidants.

\section{Open Field Test}

The values are expressed as the mean \pm SEM of six animals. Superscripts showed the statistical significance by ANOVA followed by Dunnett's test. aP $<0.001$ represents the significance of group II with Group I. bP $<0.05$ represents the significance on Group III with II. $c \mathrm{P}<0.01$ represents statistical significance of group IV, V vs. III.

\section{Histopathology}

Histopathology of mice brain were taken from the normal saline group, negative control group, MA, MF-S and MF-T treated groups and the results were analyzed. In the prodrug treated group, all the two different ester prodrugs shown normal cells of cortex without any spongiform cells, indicated the protective effect of synthesized natural compound conjugating ester prodrugs.

\section{DISCUSSION}

The two natural phenolic antioxidant conjugated mefenamic acid prodrugs were synthesized and physical chemical characterization confirmed the structure and purity of the novel compounds, MF-S and MF-T.

The MF-S and MF-T produced enhanced anti-inflammatory activity and showed a sustained release pattern by using carrageenan induced paw oedema method. Many studies showed that the carrageenan inducing the paw oedema. The oedema induced by carrageenan produced acute and local inflammatory response. ${ }^{26}$ The conjugates used in this study, sesamol and thymol, also produced anti-inflammatory activity and antioxidant processes. ${ }^{27}$ Therefore overall, the synthesized products showed synergistic anti-inflammatory activity.

There are many report suggesting that the main side effect of NSAIDs is the production of gastric ulceration because of the free carboxyl functional group in the NSAIDs. ${ }^{28}$ So the prodrug based synthetic approach on MA by using antioxidant showed significant reduction of gastric ulcer formation due to the modification of the free carboxylic acid group present in the NSAID and also by the protective nature of antioxidants.

MF-S and MF-S showed the significant protective effect against the neurotoxicity produced by the aluminium chloride. Literature survey suggested that the $\mathrm{AlCl}_{3}$ alters the behavioural and neurotransmitter as well as learning and memory.29 Aluminium gets deposited in brain regions, after exposure to long duration, specifically in hippocampus and cortex and leads to the degenerative diseases such as $A D$ (Alzheimer's Disease) and PD (Parkinson's Disease). ${ }^{30,31}$ There are several studies that revealed the aluminium toxicity in brain leads to cognitive dysfunction ${ }^{32}$ and locomotor problems. ${ }^{33}$ The effect in the brain can be tested by the behavioural tests such as open field test, Marble burying test ${ }^{34}$ and Water maze test ${ }^{35}$ in which the memory and motor activity was decreased. But it was observed that the considerable enhancement of the cognitive and motor activities in the prodrug treated groups. The reports showed that the antioxidant SOD (Superoxide dismutase) ${ }^{36}$ and catalase ${ }^{37}$ showed protective effect in brain against the degenerative conditions. In vivo antioxidant test of MF-S and MF-T done and the comparative study against the MA proved the increased SOD and catalase in the prodrug treated groups. The outcome of the present investigation proved the enhanced antiinflammatory activity, reduction in gastric toxicity and protective activity in the central nervous system.

\section{CONCLUSIONS}

The ester prodrugs of MA were successfully synthesized, and the study proved the enhanced pharmacological activities of MA by prodrug approach with a reduction in side effects. Also, remarkable improvement in the transport properties across the BBB was seen. Pharmacological studies showed enhanced anti-inflammatory activity and significant decrease in the ulcerogenic index. This research work also attempted to reveal the role of NSAID in neurodegenerative conditions. This study showed remarkable brain distribution of the MF-S and MF-T in the brain with notable protective action against the neurodegenerative conditions. The prodrug based synthetic approach successfully attains the goal to improve the therapeutic and transport profile with a reduction in the toxicity profile of the NSAIDs.

Data sharing statement provided by the authors is available with the full text of this article at jemds.com.

Financial or other competing interests: None.

Disclosure forms provided by the authors are available with the full text of this article at jemds.com.

\section{REFERENCES}

[1] Kemisetti DP, Manda S, Aukunuru J, et al. Synthesis of prodrugs of mefenamic acid and their in vivo evaluation. Int J Pharm Pharm Sci 2014;6(7):437-42.

[2] Ullah N, Huang Z, Sanaee F, et al NSAIDs do not require the presence of a carboxylic acid to exert their anti- 
inflammatory effect - why do we keep using it? J Enzyme Inhib Med Chem 2016;31(6):1018-28.

[3] Yue Q, Peng Y, Zhao Y, et al. Dual-targeting for brainspecific drug delivery: synthesis and biological evaluation. Drug Deliv 2018;25(1):426-34.

[4] Kushwaha P, Singh N, Gupta A, et al. Phytochemical and pharmacological insight on sesamol: an updated review. Current Bioactive Compounds 2020;16:1.

[5] Meeran MFN, Javed H, Al Taee H, et al. Pharmacological properties and molecular mechanisms of thymol: prospects for its therapeutic potential and pharmaceutical development. Front Pharmacol 2017;8:380.

[6] Dubey S, Valecha V. Prodrugs: a review. World Journal of Pharmaceutical Research 2014;3(7):277-97.

[7] Wongrakpanich S, Wongrakpanich A, Melhado K, et al. A comprehensive review of non-steroidal antiinflammatory drug use in the elderly. Aging Dis 2018;9(1):143-50.

[8] Gilles V, Vieira MA, Lacerda V. A new, simple and efficient method of steglich esterification of juglone with longchain fatty acids: synthesis of a new class of nonpolymeric wax deposition inhibitors for crude oil. Journal of the Brazilian Chemical Society 2015;26(1):74-83.

[9] Matsumoto K, Yanagi R, Oe Y. Recent advances in the synthesis of carboxylic acid esters. IntechOpen 2018. DOI: 10.5772/intechopen.74543.

[10] Jilani JA, Idkaidek NM, Alzoubi KH. Synthesis, in vitro and in vivo evaluation of the $\mathrm{N}$-ethoxycarbonylmorpholine ester of diclofenac as a prodrug. Pharmaceuticals (Basel, Switzerland) 2014;7(4):453-63.

[11] Cai L. Thin layer chromatography. Curr Protoc Essential Lab Tech 2014;8(1):6.3.1-6.3.18.

[12] Rasheed A, Ashok Kumar CK. Design, synthesis, hydrolysis kinetics and phamacodynamic profiles of histidine and alanine conjugates of aceclofenac. Acta Pharm 2010;60(1):99-109.

[13] Ashraf Z, Alamgeer, Kanwal M, et al. Flurbiprofenantioxidant mutual prodrugs as safer nonsteroidal antiinflammatory drugs: synthesis, pharmacological investigation, and computational molecular modeling. Drug Des Devel Ther 2016;10:2401-19.

[14] Schrodinger Release 2020-1: Prime, Schrödinger, induced fit docking protocol. Glide, Schrödinger. New York, NY: LLC 2020.

[15] Zhang $X$, Liu X, Gong T, et al. In vitro and in vivo investigation of dexibuprofen derivatives for CNS delivery. Acta Pharmacol Sin 2012;33(2):279-88.

[16] Peesa JP, Atmakuri LR, Yalavarthi PR, et alOxaprozin prodrug as safer nonsteroidal anti-inflammatory drug: Synthesis and pharmacological evaluation. Archiv der Pharmazie Chemistry in Life Sciences 2018;351(2):1700256.

[17] Al Batran R, Al-Bayaty F, Al-Obaidi MMJ, et al. In vivo antioxidant and antiulcer activity of parkia speciosa ethanolic leaf extract against ethanol-induced gastric ulcer in rats. PLoS One 2013;8(5):e64751.

[18] Al-Amin M, Chowdury M, Amin I. Levocarnitine improves $\mathrm{AlCl} 3$ induced spatila working memory impairment in swiss Albino mice. Front Neurosci 2019;13:278.
[19] Seibenhener ML, Wooten MC. Use of the open field maze to measure locomotor and anxiety-like behavior in mice. J Vis Exp 2015;(96):e52434.

[20] Angoa-Perez M, Kane MJ, Briggs DI, et al. Marble burying and nestlet shredding as tests of repetitive, compulsivelike behaviors in mice. J Vis Exp 2013;(82):50978.

[21] Nunez J. Morris water maze experiment. J Vis Exp 2008;(19):897.

[22] Kakkar P, Das B, Viswanathan PN. A modified spectrophotometric aasay of superoxide dismutase. Indian J Biochem Biophys 1984;21(2):130-2.

[23] Khan RA, Khan MR, Sahreen S. Brain antioxidant markers, cognitive performance and acetylcholinesterase activity of rats: efficiency of Sonchus asper. Behav Brain Funct 2012;8:21.

[24] Portia AG, Mwaniki DM, Wanjala PM, et al. Evaluation of in vivo and in vitro antioxidant properties of the ethanol leaf extract of culcasia falcifolia. J Biomed Pharm Sci 2018;1(2):1000114.

[25] Alturkistani HA, Tashkandi FM, Mohammedsaleh ZM. Histological stains: a literature review and case study. Glob J Health Sci 2015;8(3):72-9.

[26] Mansouri MT, Hemmati AA, Naghizadeh B, et al. A study of the mechanisms underlying the anti-inflammatory effect of ellagic acid in carrageenan-induced paw edema in rats. Indian J Pharmacol 2015;47(3):292-8.

[27] Bardaweel SK, Tawaha KA, Hudaib MM. Antioxidant, antimicrobial and antiproliferative activities of Anthemis palestina essential oil. BMC Complement Altern 2014;14:297.

[28] Höer A, Gothe H, Schiffhorst G, et al. Comparison of the effects of diclofenac or other non-steroidal antiinflammatory drugs (NSAIDs) and diclofenac or other NSAIDs in combination with proton pump inhibitors (PPI) on hospitalisation due to peptic ulcer disease. Pharmacoepidemiol Drug Saf 2007;16(8):854-8.

[29] Nampoothiri M, John J, Kumar N, et al. Modulatory role of simvastatin against aluminium chloride-induced behavioural and biochemical changes in rats. Behavi Neuro 2015;2015:210169.

[30] Deloncle R, Guillard O. Mechanism of Alzheimer's disease: arguments for a neurotransmitter aluminium complex implication. Neurochem Res 1990;15(12):1239-45.

[31] Julka D, Vasishta RK, Gill KD. Distribution of aluminum in different brain regions and body organs of rat. Bio Trace Element Res 1996;52(2):181-92.

[32] Erazi H, Sansar W, Ahboucha S, et al. Aluminum affects glial system and behavior of rats. Comptes Rendus Biologies 2010;333(1):23-7.

[33] Khan KA, Kumar N, Nayak PG, et al. Impact of caffeic acid on aluminium chloride-induced dementia in rats. J Pharmacy Pharmacol 2013;65(12):1745-52.

[34] Lazic SE. Analytical strategies for the marble burying test: avoiding impossible predictions and invalid p-values. BMC Res Notes 2015;8:141.

[35] Vorhees CV, Williams MT. Morris water maze: procedures for assessing spatial and related forms of learning and memory. Nat Protoc 2006;1(2):848-58.

[36] Mavelli I, Rigo A, Federico R, et al. Superoxide dismutase, glutathione peroxidase and catalase in developing rat brain. Biochem J 1982;204(2):535-40. 


\section{Jemds.com}

[37] Moraes TB, Jacques CED, Rosa AP, et al. Role of catalase and superoxide dismutase activities on oxidative stress in the brain of a phenylketonuria animal model and the
Original Research Article

effect of lipoic acid. Cell Mol Neurobiol 2013;33(2):25360. 